\title{
Brief Communication: Unusual Pathological Condition in the Lower Extremities of a Skeleton From Ancient Israel
}

\author{
Mark Spigelman and Helen D. Donoghue* \\ Department of Medical Microbiology, University College London, London WIT 6JF,UK
}

Hershkovitz et al. (1992) reported on a skeleton from Bet Guvrin, Israel, dating from the Byzantine period (300-600 AD). There were pathological changes in the lower extremities, which presented significant diagnostic problems. Their original diagnosis was Madura foot, based on the absence of typical medullary changes associated with osteomyelitis, and to the presence of severely ankylosed (left calcaneal talar joint) and deformed bilateral foot bones. However, Manchester (1993), in reply, noted that Madura foot is usually a predominantly unilateral condition, and that many of the surface changes were consistent with secondary pyogenic infections following plantar ulceration associated with leprous peripheral neuropathy. There was evidence that at least one joint was a typical Charcot's joint suggestive of the presence of some form of neuropathy. Manchester (1993) noted that this skeleton was from the same period as one reported by Zias (1985), which was the first ancient skeleton from which Mycobacterium leprae DNA was extracted and amplified (Rafi et al., 1994). In further reply, Hershkovitz et al. (1993) admitted that the pathological features could fit a diagnosis both Madura foot and leprosy, but still considered Madura foot the more likely. Here the controversy rested.

As the controversy has remained unresolved, one of the bones from the foot was sent to us by Professor Israel Hershkovitz of the Department of Anatomy and Anthropology, Tel Aviv University, Israel, for further examination. The aim was to determine whether M.leprae DNA was present in this specimen, as mycobacterial DNA has been shown to persist in samples of a similar age (Rafi et al. 1994; Donoghue et al. 1998). Even in the case of lepromatous leprosy, the numbers of bacilli in peripheral sites are not believed to be high. Therefore, the specimen was examined using a specific nested polymerase chain reaction (PCR), to determine whether M.leprae -specific DNA could be detected.

Two sets of M.leprae -specific nested primers were designed. The first were based on the M. leprae repetitive element RLEP, which is reported to be present at 28 copies/cell. These gave an outer product of $129 \mathrm{bp}$ and a $99 \mathrm{bp}$-nested product. Those based on the $18 \mathrm{kD}$ antigen $(\mathrm{Ag})$ gene gave a product of $136 \mathrm{bp}$ (outer) and $110 \mathrm{bp}$ (inner). The sequences and locations of these primers are listed in Table 1. 
Stringent precautions were taken to avoid cross-contamination. Briefly, clean protective clothing was worn with frequent glove changes. Pipettors and surfaces were cleaned with neat household liquid detergent, rinsed with ultrapure water, and dried with ethanol before use. Sterile tubes and plugged tips were used. A separate roon was used for handling PCR products, with a different set of pipettors and protective clothing.

The DNA extraction method was essentially the second protocol described by Donoghue et al. (1998), and negative controls were processed alongside the sample. Pre-aliquoted doublestrength PCR mix was used (Advanced Biotechnologies, Ltd., Epsom, UK). The final composition of the PCR mixture $(50 \mu \mathrm{l})$ was $75 \mathrm{mmol}^{-1}$ Tris-HCl $(\mathrm{pH} 8.8) ; 20 \mathrm{mmol}^{-1}\left(\mathrm{NH}_{4}\right)_{2} \mathrm{SO}_{4} ; 1.5 \mathrm{mmol}^{-1}$ $\mathrm{MgCl}_{2} ; 0.01 \%$ Tween $20 ; 200 \mu \mathrm{mol}^{-1}$ (each) dATP, dCTP, dGTP, and dTTP; and 1.25 units Taq DNA polymerase. Bovine Serum Albumin (BSA) was added to give a final concentration of 10 $\mathrm{mM}$. The primer pair, BSA, and DNA preparations $(5.0 \mu \mathrm{l})$ were added to each pre-aliquoted tube plus sufficient water to bring the volume to $50 \mu \mathrm{l}$. A tube with water in place of template was always included as a negative control. Primers were used at a final concentration of $60 \mathrm{nM}$ (RLEP primers), $100 \mathrm{nM}$ (18-kD Ag inner primers), and $200 \mathrm{nM}$ (18-kD Ag outer primers).

Nested PCR was carried out using a two-tube procedure. In the first stage the outer primers were added to the PCR mix. Amplification was carried out with one cycle of strand separation at $94 \mathrm{oC}$ for $4 \mathrm{~min} ; 25$ cycles of $94^{\circ} \mathrm{C}$ for $40 \mathrm{~s}$; . annealing at $55^{\circ} \mathrm{C}(18 \mathrm{kD} \mathrm{Ag}$ gene primers $)$ or $58^{\circ} \mathrm{C}$ (RLEP primers) for $1 \mathrm{~min}$; and strand extension at $72^{\circ} \mathrm{C}$ for $20 \mathrm{~s}+1 \mathrm{~s}$ increment per cycle. There was a final $1 \mathrm{~min}$ at $72^{\circ} \mathrm{C}$ for further strand extension. In the second stage of nested PCR, new tubes of PCR mix were used, with the inner primers, with 5.0 $\mu 1$ of stage one product used as the DNA template. This second stage PCR cycle was identical to the first. PCR products were detected by agarose gel electrophoresis and recorded by Polaroid camera.

Positive results were obtained using both primer pairs, although there was an extremely weak positive with the PCR for the single-copy $18-\mathrm{kD} \mathrm{Ag}$ gene. Because of the low quantity of amplicon, only a partial sequence from the RLEP primers was obtained. However, those obtained from other archaeological samples showed a sequence identical with that of M.leprae. A preliminary sequence of $123 \mathrm{bp}$ was obtained from the reverse inner primer, which includes part of the outer forward primer (underlined), the forward and reverse inner primers (bold) and all the intervening DNA:

GCATGTCATG[C]NNTTGAGGTGTCGGCGTGGTCAATGT-GCCGCACC[N] TGAACAGGCAC[G]GTCCCCG-GCACGGTATA[G]CTATTCGCACCTGATG TTATCCCTTGCACCATTTCTG

There are 3 missing or indeterminate values and 2 doubtful results in the sequence between the inner primers, plus 2 indeterminate and one doubtful result in the forward primer region. Otherwise the sequence was identical to 30 sequences of $M$. leprae held in the gene data bank. With the exception of an internal 18 bp sequence, a BLAST search of the gene database held by the National Center for Biotechnology Information showed that this product is unique to M.leprae.

The primers used have been described elsewhere (Donoghue et al.,1999) and have been shown to be both specific and extremely sensitive, capable of detecting less than one leprosy bacillus. The pathology, plus the demonstration of $M$. leprae DNA in the specimen, indicates that the individual was suffering from leprosy (Hansen's disease).

Mycetoma, also known as Madura foot, is a local, chronic, slowly progressive disease with the classic presentation involving tumefaction, multiple draining sinuses, and grain-filled pus. Either a bacterium (actinomycetoma) or a fungal (eumycetoma) organism is the primary cause. Many different organisms have been reported as causal agents in the literature. The majority are soil environmental saprophytes (McGinnis 1996).

Hershkovitz et al.. (1992) thought it likely that the skeleton was of an immigrant rather than a local resident, although this was based on very limited numbers of cases of Madura foot in Israel of which they were aware. However, the current literature includes reports of cases from Great Britain, the USA, Bulgaria, and the Middle East. Therefore, it is possible that the individual was a 
native of the area and had a coincidental or secondary case of Madura foot caused by local environmental organisms. Mixed or secondary infections are ubiquitous in peripheral M.leprae infection, and possibly exacerbated by the decrease in cell mediated immunity. $A$ further suggestion is that a malignant condition may have arisen at the site of a trophic ulcer. However,infections, as is shown even in the present day (Dr J. Mehta, The Bandorawalla Leprosy Hospital, Pune, India, and Dr T. Oomen, Department of Pharmacology, Manipal, India, personal communications).

Although it is not possible to prove the sequence of events that led to the palaeopathological features in this individual, we conclude that the underlying disease in this case

\section{ACKNOWLEDGEMENTS}

Professor Israel Hershkovitz, Department of Anatomy and Anthropology, Tel Aviv University, Israel provided the bone sample. This work was reported on briefly at the International Congress on the Past and Present of Leprosy, July 26-31, 1999, in Bradford, UK.

\section{LITERATURE CITED}

Donoghue HD, Spigelman M, Zias J, Gernaey-Child AM, Minnikin DE. 1998 Mycobacterium tuberculosis complex DNA in calcified pleura from remains 1400 years old. Lett Appl Microbiol 27:265-269.

Donoghue HD, Spigelman M.,M, Holton J. PCR primers that can detect low levels of Mycobacterium leprae DNA. J Med Microbiol (in press).

Hershkovitz I, Spiers M, Katznelson A., $\underline{A}$, Arensberg B. 1992. Unusual pathological conditions in the lower extremities of a skeleton from ancient Israel. Am J Phys Anthropol 88:23-26.

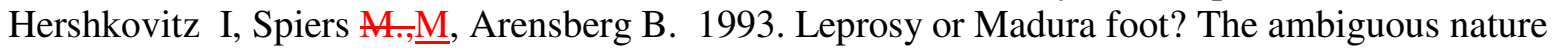
of infectious disease in paleopathology: reply to Dr Manchester. Am J Phys Anthropol 91:251253.

Manchester K. 1993. Unusual pathological condition in the lower extremities of a skeleton from ancient Israel. Am J Phys Anthropol 91:249-250.

McGinnis MR. 1996. Mycetoma. Dermatol Clin 1:97-104.

Rafi A, Spigelman M, Stanford J, Lemma E, Donoghue H, Zias J. 1994. DNA of Mycobacterium leprae detected by PCR in ancient bone. Int J Osteoarchaeol 4:287-290.

Zias J. 1985. Paleopathological evidence of leprosy in Palestine during the Talmudic period. Koroth 9:242-248. 
TABLE 1 Sequences of oligonucleotide primers for M.leprae ${ }^{1}$

$\begin{array}{lrc}\text { Primer } & \text { Residue } & \text { Sequence } \\ \text { LP1 } & 490-509 & \text { TGCATGTCATGGCCTTGAGG } \\ \text { LP2 } & 618-599 & \text { CACCGATACCAGCGGCAGAA } \\ \text { LP3 } & 505-522 & \text { TGAGGTGTCGGCGTGGTC } \\ \text { LP4 } & 603-586 & \text { CAGAAATGGTGCAAGGGA } \\ \text { LP5 } & 1050-1070 & \text { ATCGACTGTTGTTTGCGCAAC } \\ \text { LP6 } & 1159-1139 & \text { CCAGCAACCGAAATGTTCGGA } \\ \text { LP7 } & 1037-1057 & \text { TCATAGATGCCTAATCGACTG } \\ \text { LP8 } & 1172-1154 & \text { GGCACATCTGCGGCCAGCA }\end{array}$

${ }^{1}$ For primers LP1-LP4 the primer sequence is found in the M.leprae RELP3 sequence X17153. For primers LP5-LP8 the primer sequence is found in the M.leprae $18 \mathrm{kD} \mathrm{Ag}$ gene sequence MSGANT18K. 